\title{
Aproximaciones a una propuesta de educación para la paz con perspectiva de género para el caso del postconflicto colombiano
}

\author{
Clara Esperanza Pedraza Goyeneche ${ }^{1}$ \\ Recibido: 23-05-2020 \\ Aceptado: 17-06-2020
}

\section{Resumen}

Las mujeres en América Latina han sido víctimas de la violencia en el conflicto armado; por ello - como respuesta a la violencia vivida - han optado por participar en la construcción de la paz. En el caso colombiano, las mujeres lograron incluir en el Acuerdo Final de paz la transversalización del enfoque de género, de tal manera que esta acción se constituyó en un hito histórico que invitó a la reflexión acerca de cuál es el rol de la mujer en la construcción de la paz y cuáles son las condiciones de formación más apropiadas para potenciar su liderazgo, en el camino hacia una paz perdurable y sostenible. Esta pregunta justificó esta investigación sobre educación, género y paz que se propuso diseñar una propuesta educativa para la construcción de relaciones de género saludables, equitativas y pacíficas, en el postconflicto en Colombia. Este artículo muestra los resultados de la fase exploratoria de la investigación, que explican la percepción que tenían 134 hombres y mujeres excombatientes de las FARC-EP, en el año 2018, en relación con la transversalización de la perspectiva de género en el Acuerdo Final de paz.

\footnotetext{
1. Doctoranda en Estudios Interdisciplinares de Género, Universidad Rey Juan Carlos, España. Correo electrónico: clara.pedraza@unad.edu.co

ORCID: https://orcid.org/0000-0002-0150-5399

Google Scholar: https://scholar.google.com/citations?hl=es\&user=lkFvofwAAAAJ
} 
Palabras clave: paz, educación, mujer, mujer y desarrollo, conflicto armado, igualdad de oportunidades.

\title{
Approaches to a proposal for education for peace with a gender perspective in the case of the Colombian post-conflict
}

\begin{abstract}
Women in Latin America have been victims of violence in the armed conflict; so, as a response to the violence experienced, some have chosen to participate in peacebuilding. In Colombia, women -in the peace agreement context- managed to include the mainstreaming of the gender approach. This fact constituted a historical milestone that invited reflection on the role of women in peacebuilding and the appropriate educational training conditions to enhance their leadership, in the way to enduring and sustainable peace. These issues justified this research on education, gender, and peace, which proposed to design an educational training proposal for the construction of healthy, equitable, and peaceful gender relationships in the post-conflict in Colombia. This paper shows the results of the investigation exploratory phase, and it explains the perception that 134 men and women ex-FARC combatants had in Colombia in 2018, regarding the mainstreaming of the gender perspective in the final peace agreement.
\end{abstract}

Keywords: peace education, gender roles, women, conflict research, armed conflicts $\rightarrow$ war, equal opportunity. 


\section{Introducción}

La violencia contra las mujeres ha estado presente en los ámbitos familiar, académico, laboral, profesional y político. Igualmente, a lo largo de la historia las mujeres han sido sujeto de violencia en los contextos de la guerra, viviendo situaciones y problemáticas derivadas de hechos tales como:

La violencia armada continua y su impacto diferencial en hombres, mujeres, niños y niñas; creciente incidencia de la violencia sexual y otras formas de violencia de género (VSG) durante y después de la violencia armada; el desplazamiento y la separación de los individuos y las familias; riesgos para la salud de la mujer; limitaciones a los medios de sustento y superación económica de la mujer; restricciones en el acceso de mujeres y niñas a la educación; y cambios en los roles de género. (ONU Mujeres y POTI, 2013).

No obstante, históricamente también la relación entre las mujeres y la paz en el mundo ha marcado hitos relevantes por su papel en la sociedad, especialmente en contextos de guerra o de conflicto armado, aun cuando hayan prevalecido sociedades patriarcales y excluyentes en relación con las oportunidades a las que las mujeres deben tener derecho en los aspectos políticos, sociales y de toma de decisiones de todo orden. Es así como, en algunas sociedades del mundo, las mujeres son llamadas a ser sujetos de la paz, en un proceso resiliente y emancipador que subyace a las vivencias propias y particulares de la guerra en cada sociedad. Desde la ONU se ha venido promoviendo un escenario de implementación e instrumentalización normativa a partir de acuerdos establecidos entre sus países miembros. Por ello, la Agenda 2030 para el Desarrollo Sostenible plantea:

el objetivo de lograr la igualdad de género y empoderar a todas las mujeres y las niñas; asegurar la participación plena y efectiva de las mujeres y la igualdad de oportu- 
nidades de liderazgo a todos los niveles decisorios en la vida política, económica y pública. (Unesco, 2017).

En América Latina, a través de la Estrategia de Montevideo, aprobada en la XIII Conferencia Regional sobre la Mujer de América Latina y el Caribe en octubre de 2016, se establecieron los ejes para la implementación de la agenda regional de género en el marco del desarrollo sostenible hacia 2030. En este escenario, se destaca la necesidad de fortalecer la promoción de la autonomía de las mujeres en tres expresiones: física, económica y en la toma de decisiones, describiéndolas así:

i) la autonomía económica, que se vincula con la posibilidad de controlar los activos y recursos; ii) la autonomía física, que se refiere a la capacidad para decidir libremente acerca de la sexualidad, la reproducción y el derecho a vivir una vida libre de violencia, y iii) la autonomía en la toma de decisiones, que implica la plena participación en las decisiones que afectan la vida de las mujeres, sus familias, sus comunidades y la sociedad en su conjunto. (Cepal, 2016, p. 37)

En Colombia, dado el conflicto armado que ha vivido el país por más de 50 años, el Gobierno ha desarrollado una ruta hacia la construcción de una paz duradera y sostenible en donde los diálogos de paz con los grupos armados al margen de la ley se han convertido, quizá, en la estrategia de gobierno más importante para alcanzar esta meta. Por esta razón, logró suscribir en el año 2016 el Acuerdo General para la Terminación del Conflicto y la Construcción de una Paz Estable y Duradera con uno de los grupos armados al margen de la ley, las FARC-EP. El acuerdo incorpora una perspectiva de género sobre los supuestos de encontrar en la participación activa de la mujer: a) una sociedad más democrática, b) el reconocimiento de la importancia del liderazgo de la mujer en la prevención y solución de los conflictos y en la consolidación de la paz, c) el análisis de las consecuencias de las graves infracciones al derecho internacional humanitario, d) el análisis de las graves violaciones a los derechos humanos come- 
tidas contra mujeres y niñas o contra la población LGBTI, y e) la necesidad de generar condiciones para que la mujer víctima se convierta en constructora de paz.

\section{Durante los diálogos para el acuerdo se creó}

la Subcomisión de Género y se le encarga revisar y garantizar con el apoyo de expertas y expertos nacionales e internacionales que los acuerdos alcanzados tengan un adecuado enfoque de género y que este proceso también posibilite bases sólidas que garanticen una paz estable y duradera en la implementación territorial. (Fundación Paz y Reconciliación, 2017, p. 229)

En consecuencia, el plan marco de implementación del acuerdo final de paz en Colombia planteó un énfasis en la educación rural con las siguientes estrategias: a) fortalecimiento de la educación técnica, tecnológica y universitaria, b) atención de la primera infancia, c) calidad y permanencia en la educación rural, d) incentivos a la formación profesional no tradicional para mujeres, e) eliminación del analfabetismo, f) cobertura de educación rural para preescolar, g) educación para básica y media, h) educación para la recreación, cultura y deporte e i) la estrategia de ciencia, tecnología e innovación para el desarrollo rural.

Desde este contexto, se decidió adelantar un ejercicio de investigación exploratoria con el fin de dar respuesta al siguiente interrogante, que se constituyó en una pregunta que antecedió la formulación del problema de investigación: ¿cuál es el rol de la mujer en la construcción de la paz y cuáles son las condiciones de formación más apropiadas para potenciar su liderazgo en el camino hacia una paz perdurable y sostenible?

Y para ello se seleccionó el siguiente público objetivo: $73 \mathrm{mu}-$ jeres, 60 hombres y una persona no registró sexo al que pertenece. Estas personas pertenecen a un grupo de excombatientes del movimiento exguerrillero de las FARC-EP, con edades de 18 a 58 años. De igual forma se efectuó una entrevista a profundidad a 
una mujer excombatiente con rango de jerarquía durante su militancia en el grupo guerrillero.

Al mismo tiempo, se quiso confirmar si el siguiente propósito se constituía en una necesidad real y por atender en el público objetivo: diseñar una propuesta de formación integral para la autonomía de la mujer, su empoderamiento y el desarrollo de capacidades emancipadoras, así como de nuevas masculinidades, en el escenario del postconflicto colombiano; su abordaje se plantea a partir de tres aspectos: 1) el rol de la mujer en la construcción de paz, su autonomía y capacidad emancipadora; 2) el tipo de masculinidades que, junto a los dos anteriores elementos, conducirían a 3) la construcción de relaciones de género saludables, equitativas y pacíficas, trascendiendo el acuerdo de paz para facilitar el camino hacia la consolidación de la paz con educación.

\section{Marco teórico}

El abordaje del objetivo desde los tres aspectos mencionados condujo a establecer unos presupuestos teóricos que orientaran la investigación. En la fase exploratoria se tuvieron en cuenta los siguientes.

El análisis de la violencia. Esta se abordó desde los planteamientos que vienen del enfoque ecológico, a partir de la teoría de desarrollo humano de Bronfenbrenner, con la cual se estudian los factores relacionados con la violencia de género a nivel de la sociedad, la comunidad, la familia y el individuo, entendiendo el desarrollo humano "en términos de una progresiva acomodación mutua entre un ser humano activo, que está en proceso de desarrollo, y las propiedades cambiantes de los entornos inmediatos en los que esa persona en desarrollo vive" (Bronfenbrenner, 1979, citado por Christiansen, 2013).

De igual forma, desde los estudios de Galtung se analizan aspectos esenciales que surgen de tener en cuenta lo que significa 
pasar de los acuerdos de paz a la verdadera consolidación de la paz, así como la superación de distintos tipos de violencia:

La violencia directa es la violencia manifiesta, es el aspecto más evidente de esta. Su manifestación puede ser por lo general física, verbal o psicológica. La violencia estructural se trata de la violencia intrínseca a los sistemas sociales, políticos y económicos mismos que gobiernan las sociedades, los Estados y el mundo. Su relación con la violencia directa es proporcional a la parte del iceberg que se encuentra sumergida en el agua. La violencia cultural son "aquellos aspectos de la cultura, en el ámbito simbólico de nuestra experiencia (materializado en la religión e ideología, lengua y arte, ciencias empíricas y ciencias formales -lógica, matemáticas-, símbolos: cruces, medallas, medias lunas, banderas, himnos, desfiles militares, etc.), que puede utilizarse para justificar o legitimar la violencia directa o estructural" (Galtung, 2003b). Sería la suma total de todos los mitos, de gloria y trauma y demás, que sirven para justificar la violencia directa (Galtung, 1998). ( Calderón, 2009)

La reflexión sobre violencia de género y violencia contra las mujeres se abordó desde aportes significativos como los que explica Portolés (2014), quien las ha enfocado desde la lingüística como categoría analítica.

Así mismo, se analizaron algunos fundamentos de la teoría feminista desde los estudios que han realizado Amorós y Miguel (2010), en los cuales se plantea la importancia de resignificar tanto el concepto de género como el de patriarcado para avanzar en la reconstrucción del sujeto. Es así como Celia Amorós y Ana de Miguel (2010) plantean que

la socialización de género, tiende en primer lugar a inducir una identidad sexuada, determina un rango distintivo para hombres y mujeres y prescribe un rol sexual. El patriarcado consiste fundamentalmente, en un sistema de 
dominación que se construye mediante mecanismos de autodesignación que marcan la pertenencia al conjunto de dominadores $y$, correlativamente, mediante el de la heterodesignación, de las dominadas. (Amorós y Miguel, 2010).

En ese sentido, desde las sociedades patriarcales se ha justificado la violencia contra las mujeres, ya que han estado basadas en conceptualizaciones sobre la mujer, tal y como lo refiere Miguel (2005):

La violencia contra las mujeres, aún en medio de un universo de violencia presenta claves específicas. Es decir, formas específicas de legitimación, basadas no en su condición de personas sino de mujeres. Esta legitimación procede de la conceptualización de las mujeres como inferiores y como propiedades de los varones, a los que deben respeto y obediencia. (Miguel, 2005, § 11)

De igual forma, siendo la guerra un escenario de violencia de género, fue revisado el papel de las mujeres en la guerra de acuerdo con los estudios de Quesada (2014) y Ahmed Ali (2015). Uno de los aspectos abordados por Quesada (2014) tiene que ver con la identidad femenina que representa la mujer en un contexto de guerra y las razones por las cuales las mujeres son violentadas en esos contextos:

En las guerras de los últimos años del siglo $X X$, frecuentemente aparece mezclado el conflicto étnico y de ahí que destruir la etnia es un elemento fundamental para ganar la guerra. Al ser las mujeres grupo fundamental de conservación de los valores étnicos, representan también el elemento a vencer para conseguir la victoria. (Quesada, 2014, p. 35).

No obstante, la mujer en los contextos de guerra puede ser víctima, pero a la vez puede ser combatiente y luego pasar a ejercer un rol como constructora de paz, y tanto en el contexto de paz 
como en el de la guerra su rol puede estar reconocido y asumido según la comunidad o grupo social en el que se encuentre, y la forma en que las expresiones propias de sus relaciones de género estén legitimadas. En consecuencia, en algunas culturas

las vivencias en los conflictos armados están claramente marcadas por el género. Por ejemplo, los hombres inician y dirigen las guerras, son heridos y muertos en combate; las mujeres, aunque no toman decisiones políticas o sobre seguridad, son las que más sufren las carencias. (Ahmed Ali, 2015, p. 78).

\section{Metodología}

Un acercamiento a la perspectiva de género en educación para la paz desde la investigación-acción

Teniendo en cuenta que la investigación se constituye en un elemento estructural para la reflexión y el fortalecimiento de las prácticas pedagógicas, para hacer de ella un elemento estructural en la transformación social, que se pretende lograr con la propuesta de formación de que esta se constituya en un escenario para el cambio de paradigmas, necesariamente se debe contar con la voluntad y compromiso de los actores del sistema educativo, y en el caso de esta investigación, de manera específica, de las instituciones involucradas, por lo que metodológicamente se ha planteado su desarrollo desde la investigación-acción.

La metodología de la investigación está planteada en cuatro fases, así: 1) identificación e inmersión en la problemática, 2) generación de categorías de análisis, análisis de problemas y soluciones, 3) plan de acción y 4) diseño de ruta para la implementación, evaluación y monitoreo. Para el caso del presente artículo se comentan solamente los resultados obtenidos en la primera fase. 


\section{Identificación e inmersión en la problemática}

Esta fase de exploración y contextualización tuvo como propósito identificar elementos de análisis en el marco del postconflicto colombiano sobre la triada educación, género y paz; y de manera específica conocer la percepción acerca de la transversalización de la perspectiva de género en el Acuerdo Final de Paz como parte importante del contexto que antecede el camino propuesto hacia la construcción de paz en Colombia, especialmente cuando los actores principales son los excombatientes, pues están llamados a formar parte activa de su consolidación.

Para ello, se aplicaron los siguientes instrumentos de investigación:

- 134 cuestionarios a excombatientes involucrados en el proceso de paz sobre la percepción de la perspectiva de género y su relación con la paz en el marco del postconflicto, quienes se encontraban en espacios territoriales de capacitación y reincorporación (ETCR) recibiendo formación en alfabetización y educación básica y media con la UNAD, en el marco de un convenio con el Consejo Noruego para Refugiados con el programa denominado Arando la Educación; esto con el fin de conocer la percepción sobre el enfoque de género en el acuerdo final de paz.

- 1 entrevista a profundidad a una excombatiente de las FARC-EP, y militante hoy del partido político de esta organización, para profundizar su conexión con el rol de la mujer en la construcción de la paz y las condiciones de formación más apropiadas para potenciar su liderazgo, en el camino hacia una paz perdurable.

Se aplicó un cuestionario con escala Likert en el cual el componente de género contempló ocho aspectos que nemotécnicamente se denominaron así: beneficio sin discriminación, igualdad de género, autonomía y organización, acceso a elección popular, 
fortalecimiento de organizaciones, incorporación a sustitución de cultivos, disminución de violencia sexual, acceso sin discriminación a educación.

Se efectuó la validación del instrumento por consistencia inter$n^{2}{ }^{2}$ y se procesaron las ocho preguntas. Se llevó a cabo el procesamiento de las respuestas en el programa $\mathrm{R}$, el cual arrojó un valor de coeficiente Alfa de Cronbach de 0,9142, lo que demuestra su consistencia confiable.

Tabla 1. Cuestionario aplicado.

\begin{tabular}{|c|c|}
\hline Preguntas & $\begin{array}{l}\text { Denominación nemotécnica de } \\
\text { preguntas }\end{array}$ \\
\hline $\begin{array}{l}\text { 1. Hombres, mujeres, homosexuales, heterosexuales } \\
\text { y personas con identidad diversa en Colombia podrán } \\
\text { participar y beneficiarse - sin discriminaciones y en } \\
\text { igualdad de condiciones- en el desarrollo de los } \\
\text { programas de construcción de la paz }\end{array}$ & Beneficio sin discriminación \\
\hline $\begin{array}{l}\text { 2. Las mujeres en Colombia estarán en igualdad de } \\
\text { condiciones con los hombres para la explotación y el } \\
\text { desarrollo del campo. }\end{array}$ & Igualdad de género \\
\hline $\begin{array}{l}\text { 3. Tendrán las mujeres en Colombia mayor autonomía } \\
\text { económica y posibilidades de organización. }\end{array}$ & Autonomía y organización \\
\hline $\begin{array}{l}\text { 4. Podrán participar las mujeres defensoras de derechos } \\
\text { humanos en política y el acceso a elección popular en } \\
\text { Colombia. }\end{array}$ & Acceso a elección popular \\
\hline $\begin{array}{l}\text { 5. Se fortalecerán en Colombia las organizaciones y } \\
\text { movimientos sociales de mujeres, jóvenes y población } \\
\text { LGTBI. }\end{array}$ & Fortalecimiento de organizaciones \\
\hline $\begin{array}{l}\text { 6. Se incorporarán las mujeres a los procesos de } \\
\text { sustitución voluntaria de cultivos ilícitos. }\end{array}$ & Incorporación a sustitución de cultivos \\
\hline $\begin{array}{l}\text { 7. Disminuirá la violencia sexual contra las mujeres y } \\
\text { miembros de la comunidad LGBTI en Colombia. }\end{array}$ & Disminución de violencia sexual \\
\hline $\begin{array}{l}\text { 8. Hombres, mujeres, homosexuales, heterosexuales } \\
\text { y personas con identidad diversa tendrán las mismas } \\
\text { posibilidades de acceso a la educación básica y media y a } \\
\text { la educación superior. }\end{array}$ & Acceso sin discriminación a educación \\
\hline
\end{tabular}

Fuente: elaboración propia. 


\section{Resultados}

La percepción de los excombatientes sobre el enfoque de género en el acuerdo de paz en Colombia

Figura 1. Percepción del enfoque de género en los acuerdos de paz de Colombia.

\section{Percepción del enfoque de género en los acuerdos de paz en Colombia}

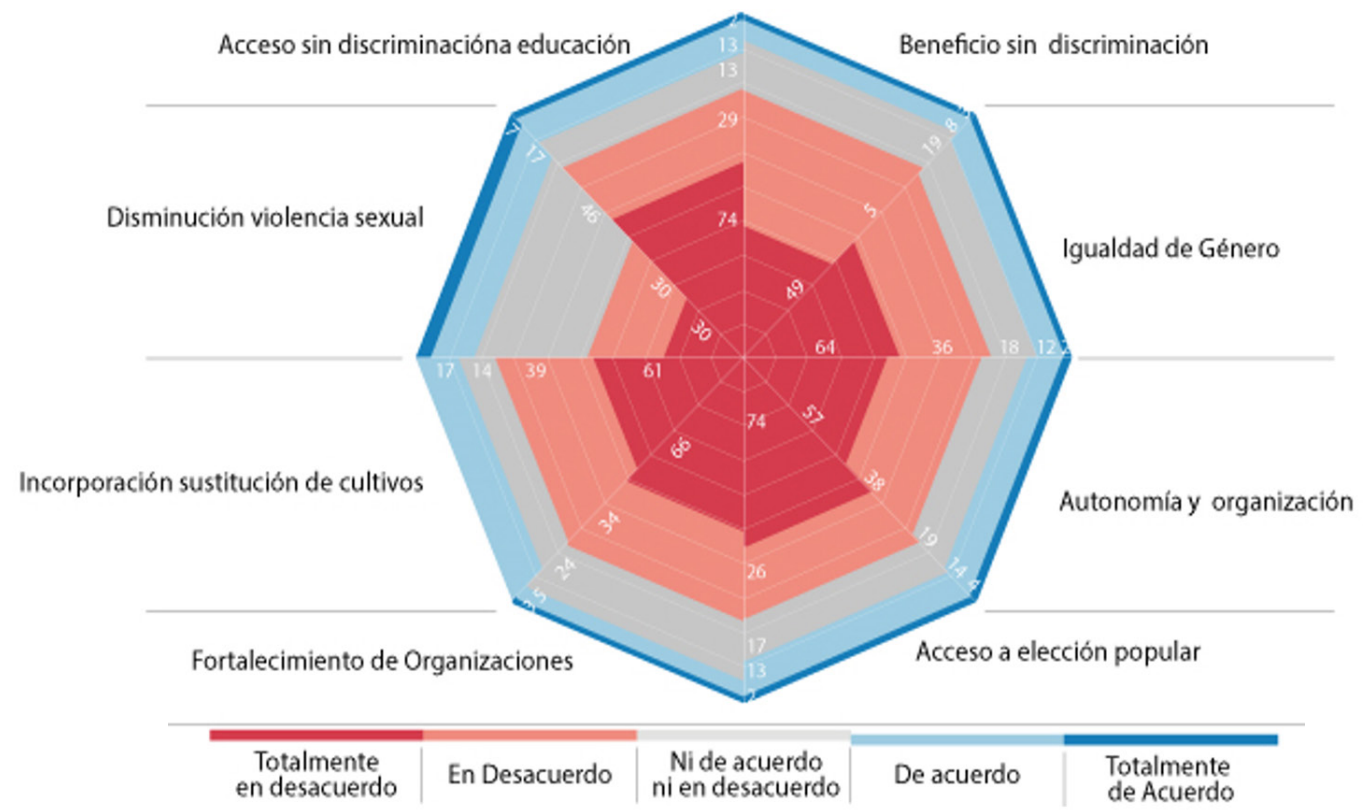

Fuente: elaboración propia.

Tal y como se observa en los resultados estadísticos (figura 1), los excombatientes expresan incertidumbre frente a la perspectiva de género y su transversalización en los acuerdos de paz, y las consecuencias que esta traería, especialmente, en términos de su impacto. Esta consideración se puede inferir dado el alto porcentaje de respuestas en las escalas: En desacuerdo y Totalmente en desacuerdo. 
No obstante, al cruzar estos resultados cuantitativos con la información cualitativa -obtenida de los comentarios que ofrecieron los participantes en relación a las preguntas y entrevistas realizadas - los aspectos más relevantes y reiterados (figura 2) se relacionan con la confianza en el acuerdo de paz, el derecho a la igualdad, la capacidad de independencia y autonomía de las mujeres, la participación, la seguridad y la educación.

Figura 2. Las seis percepciones más destacadas de los excombatientes.

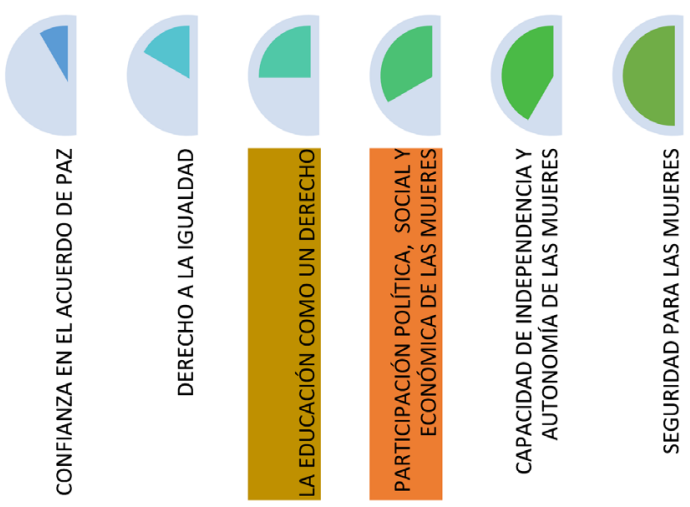

Fuente: elaboración propia.

Al respecto, en primer lugar expresan su confianza en las garantías del acuerdo de paz, las que contiene en sí mismo. Encuentran visible en los acuerdos la finalidad de avanzar hacia la igualdad y la no discriminación. Manifiestan esperanza en el acuerdo de paz y expresan que habrá paz con justicia social, pues perciben que el acuerdo como tal no permite discriminaciones.

Desde esta perspectiva, los planteamientos de Galtung (1975) cobran sentido, ya que las percepciones de los excombatientes, frente a la violencia estructural, muestran la necesidad de caminar hacia la consolidación de la paz en un escenario de confianza, en donde deben plantearse alternativas viables; de acuerdo con Galtung: "Para construir la paz se necesitan 'estructuras que eliminen las causas de las guerras y que ofrezcan alternativas al recurso a 
la violencia o la guerra cuando puedan volver a darse'" (1975, pp. 297-298).

Porque tal como lo afirman la Cámara de Comercio de Bogotá y la Organización de Estados Iberoamericanos (2019),

la construcción de la paz aspira a prevenir y resolver los conflictos violentos, además de consolidar la "paz negativa" que acompaña los acuerdos de paz (desarme, desmovilización y descenso de homicidios), [por tanto] deben abordarse tanto las causas estructurales como las intermedias y próximas de los conflictos contemporáneos. (p. 43)

Así mismo, como segundo punto destacan el derecho a la igualdad. Los excombatientes expresan un reconocimiento a los derechos bajo las premisas "todos somos iguales", "son seres humanos", "hombres y mujeres tienen los mismos derechos"; y otras de sus percepciones destacadas se relacionan con la idea de que las mujeres "son más éticas" y "mejor formadas en la igualdad". En este sentido, consideran que las mujeres tendrán las mismas condiciones para el trabajo que los hombres, dado que hoy "las mujeres desarrollan actividades y toman decisiones propias de los hombres y ayudan a los hombres". No obstante, encuentran en la discriminación limitaciones en relación al respeto a la diversidad y a la diferencia, percibiendo por ejemplo que no habrá cambios en relación con la discriminación a la comunidad LGBTI; incluso se encontró la siguiente afirmación: "esos grupos nunca van a surgir". Esta percepción mostraría una aparente comprensión de la evolución de un sistema patriarcal, pero en realidad reafirma los planteamientos de Amorós y Miguel en cuanto a la relación género-patriarcado, pues lo que existe es un rango distintivo para hombres y mujeres, que prescribe un rol sexual en un sistema de dominación:

[...] explicar la opresión de la mujer en su "infinita variedad y en su monótona similitud" [...] estarían presentes tanto las relaciones económicas como sociales y personales entre los varones y las mujeres [...]; el "sistema sexo/ género" es un término neutro que se refiere a un tipo de 
sistema sexual y generalizadamente desigual. (Amorós y Miguel, 2010).

Además, como tercer punto reconocen la capacidad de independencia y autonomía de las mujeres, reflejada especialmente en no depender de un hombre, y expresan percibir que hoy hay mayores oportunidades de empleo y salarios para las mujeres que antes. Reconocen a la mujer con mayor libertad, pues ven a la mujer rural con un liderazgo muy importante en la vida rural y lo enfatizan en afirmaciones tales como: "a las mujeres les interesa el desarrollo del campo".

De otro lado, observan que aunque las mujeres son más emprendedoras, los hombres siguen siendo quienes realizan en su mayoría las labores propias del campo y aún perciben que en la sociedad los hombres son quienes tienen mayor autonomía; algunos afirmaron: "las mujeres siempre dependerán de los hombres". En algunas de las percepciones se expresó que las mujeres no se acogerán por ejemplo a la sustitución de cultivos porque "no cambiarán sus tierras" y creen que si lo hacen, es "porque les toca". Los hombres participantes piensan que es más de su interés este aspecto y que "ellas prefieren seguir cultivando"; sin embargo, al respecto hombres y mujeres coinciden en que se requieren garantías del Gobierno.

En ese sentido, asocian la autonomía de las mujeres con la capacidad adquisitiva, pues perciben que las mujeres en Colombia pueden obtener una mayor autonomía económica y posibilidades de organización "dependiendo del Gobierno, en cuanto al apoyo económico que otorgue y si se cuenta con un buen mandatario".

En relación con esta percepción, es evidente que el pensamiento subyacente al sistema patriarcal permea el rol de la mujer en la construcción de paz desde la perspectiva del rol que le ha definido la sociedad. No obstante, es innegable que las mujeres han aportado en los procesos de construcción desde diferentes escenarios, contribuyendo al desarrollo económico, político, social, ambiental, y han sido mediadoras en procesos de desmovilización y desarme; 
tal y como lo plantea Magallón (2006), desde sus estudios sobre el rol de las mujeres en la construcción de paz,

a unas, el trabajo por la paz las lleva a un enfoque centrado en la lucha contra el militarismo, a otras, a poner el énfasis en el desarrollo de actitudes y visiones alternativas en positivo; a unas, a influir en la política internacional, a otras, a centrarse en el trabajo con la comunidad más cercana. (p. 43).

Igualmente, como cuarto aspecto expresan la necesidad de una mayor participación. Un aspecto reiterativo presente en la percepción de los excombatientes está en la necesidad de lograr mayor participación política, social y económica de las mujeres con respecto a los hombres. Consideran que esto es posible sin discriminación, a través de programas de gobierno en el proceso de construcción de paz, así como de mayor libertad de expresión.

Advierten acerca de la necesidad de generar condiciones de participación para las mujeres, quienes han sido históricamente victimizadas y aún no participan en cargos con mayor autonomía. Destacan igualmente respecto a las mujeres su capacidad de lucha, de toma de decisiones, de ser justas, por lo que consideran que las mujeres deben participar en política y tener acceso a la elección popular en Colombia, en tanto "han sido atropelladas por la guerra en Colombia y no quieren entregar más hijos al conflicto".

Al respecto, es importante resaltar que las mujeres en Colombia sin duda se han destacado por su participación en diferentes ámbitos relacionados con la paz, uno de ellos siendo defensoras de los derechos humanos, y han demostrado su liderazgo a través de movimientos sociales, ejerciendo un liderazgo transformador, el cual es un rol que debe prevalecer y ser reconocido a las mujeres, toda vez que, como lo plantea Laraña,: "Ios movimientos sociales se definen entonces como una forma de acción colectiva capaz de deslegitimar arraigados sistemas normativos y activar valores con capacidad para producir importantes cambios sociales" (Laraña, 1999, citado por Miguel, 2017, p. 250). 
Como quinto punto revelan la falta de seguridad. Este fue un aspecto insistente en los comentarios, en tanto que los excombatientes perciben falta de seguridad y una percepción de "mucho peligro". Plantean al respecto que se presentan "muertes a líderes sociales" y consideran que este es un indicador de que no existe respeto por la diversidad y la diferencia; en consecuencia, persiste la discriminación en todas partes, lo que incide igualmente en las opciones de participación.

Observan la necesidad de proteger a la mujer y expresan que a las mujeres no se les respeta, "se exponen más y aunque se encuentran liderando grupos, corren riesgos como el asesinato"; perciben que las mujeres en Colombia son las más maltratadas y piensan que no habrá cambios al respecto. Frente a esta percepción, estiman necesario el apoyo e intervención del Estado, así como la aplicación de la Constitución Política y de los acuerdos, con respeto, tolerancia y educación, y además con "una ley severa" a la vez que se genera más conciencia.

Sobre esta percepción es necesario tener en consideración que las mujeres han vivido históricamente un continuum de violencia en la sociedad y que en los contextos de guerra y después de la guerra desconfían de su seguridad. De acuerdo con los estudios sobre la violencia en contextos de guerra, se ha encontrado que,

como víctimas de la violencia de la guerra, la opresión y otras formas impuestas específicamente a las mujeres, como es el caso de las llamadas "violaciones de guerra"; como espectadoras desamparadas incapaces de salvar a sus seres queridos de la violencia del conflicto armado y de las estructuras financieras que imponen crueles privaciones; como las que acarrean con la responsabilidad y las que se preocupan sumamente por los aprietos de todas aquellas víctimas del desastre del militarismo y la militarización [...], las mujeres temen por su integridad física constantemente. Además de preocuparse por torturas, tiroteos, bombas o minas antipersonas, las mujeres y las niñas están en riesgo de sufrir violencia sexual, cada 
vez más utilizada como arma de guerra. (Jones-Demen, 2009, citada por Ahmed Ali, 2015).

Por último, como sexto punto indican que la educación es un derecho. En relación con la educación, afirman que es un derecho, y en este sentido es una exigencia de cumplimiento hacia las leyes. Por ello, piensan que se requieren garantías del Gobierno, aunque reconocen que existen varios programas y opciones. No obstante, perciben que para poder acceder a la educación se requiere de dinero. Desde esta perspectiva, se sigue pensando la educación como un derecho que aún sigue siendo negado; no obstante, en el acuerdo final de paz como tal se ha planteado un énfasis en la educación rural y la necesidad de proponer formación en carreras no tradicionales para las mujeres.

\section{La percepción desde las vivencias de una mujer excombatiente de las FARC-EP y hoy integrante del Partido Político FARC}

En entrevista con Manuela Marín, quien ejerció un papel de liderazgo en la organización guerrillera FARC-EP, para dialogar acerca de la relación entre educación, género y paz desde sus vivencias en la organización, se consignan acá los siguientes resultados por encontrarlos significativos en cuanto a lo que representa la formación y la transformación de los modelos educativos para quien viene de un contexto de guerra a sumarse a un proceso de paz.

Manuela es una mujer que desde su vida estudiantil tuvo interés por repensar el papel de la educación y el de las mujeres en la transformación social; según relata su experiencia, el hecho de haber estudiado en un colegio femenino y haber recibido formación política le permitió reflexionar y comprender — como ella misma lo expresa - la importancia de "luchar por la transformación del modelo educativo y de la sociedad general en Colombia, sino también de que nosotros las mujeres y todas esas problemáticas propias que tenemos, también deben ser tratadas de manera particular". 
A los 16 años, luego de un proceso de confrontación propio frente a la realidad del país, encuentra en la lucha armada, un escenario para pelear por una justa causa y decide formar parte de la organización guerrillera. De acuerdo con la entrevista y lo relatado por Manuela, si bien podría existir un sistema patriarcal reflejo de la sociedad, dentro de la guerrilla "no existía división sexual del trabajo", lo que hacía que para los roles de hombres y mujeres las labores complejas y de cuidado eran igualmente repartidas; en ese caso destaca que las mujeres desarrollaban labores tales como ir al combate y dirigir operativos: "Ir a combate es creo que la labor más compleja de la guerra, que implica no solamente el esfuerzo físico sino la decisión y la voluntad, que definitivamente estás entregando tu vida allí". Al respecto, de acuerdo con los estudios de Magallón (2006) es necesaria la reflexión frente a la pluralidad de comportamientos en los contextos de guerra relacionados con los roles de hombres y mujeres.

Del mismo modo, resalta que Manuela afirma "la decisión de ir a la guerra"; en ese sentido, Magallón (2006) explica que

el comportamiento de las mujeres ante la guerra no permite efectuar afirmaciones de carácter esencialista. No permite decir, por ejemplo, que las mujeres son más pacíficas que los hombres. Tampoco permite decir que los hombres son violentos por naturaleza. Aunque no impide constatar que la decisión de ir a la guerra ha estado y sigue estando salvo contadas excepciones, en manos de los hombres, y que son ellos quienes cometen y han cometido la mayoría de las acciones violentas en el mundo. Tampoco nos impide decir que las mujeres han tenido un importante protagonismo en iniciativas a favor de la paz, tanto en el pasado como en el presente. (p. 27).

Ahora bien, aunque Manuela en su entrevista expresa no haber sufrido situaciones de violencia de género, considera que, siendo las FARC-EP una organización constituida por hombres y mujeres que provienen de una sociedad violenta, la organización no es ajena a que se presenten esas situaciones, teniendo herramientas 
para resolverlas con normas internas: "eran unos estatutos, unos documentos rígidos que aplican para todas las FARC, los cuales nos permitían defendernos cuando sucedían esas cosas en contra de nosotras o de los hombres".

De igual forma, destaca los espacios democráticos en los que tenían la oportunidad de expresar situaciones particulares relacionadas con lo que les sucedía: "Y eso sí nos empoderaba porque hacía que quien pretendía ser violento, tenía necesariamente que estrellarse con esos documentos y quienes se sentían violentados, podían expresarse". Desde esta percepción, se ubica el origen de la violencia vivida en el contexto de guerra en la sociedad misma y desde la historia personal de los individuos, tal y como lo afirma Dutton, centrando las causas del maltrato en el lugar que se le da a la violencia desde los valores, actitudes y creencias compartidas por la cultura; las relaciones de fuerza y poder, y los roles en la organización social y la ideología patriarcal. En el mesosistema o exosistema representado en la comunidad se relacionan la violencia con las formas de impunidad y revictimización, la laxitud, inexistencia o incumplimiento de leyes; en el microsistema, representado en la familia, se asocia con el análisis de patrones relacionales que se despliegan redundantemente en las familias; y en el ontosistema representado por el individuo las causas de la violencia serían abordadas desde la historia personal del individuo dentro de un plano biosocial (Dutton, 1985, citado por Christiansen, 2013).

Siguiendo con la entrevista, se encontró que Manuela logró dentro de la organización posiciones de liderazgo, que alcanzó, según relata, a través de la cualificación especializada recibida allí mismo:

En el proceso de formación de cuadros de cualificación de los individuos, de quienes estábamos allí, hacía que nos fuéramos también especializando en ciertas tareas [...]. Esto hacía que nos fuéramos como conduciendo hacia una profesión [...], partícipe de los procesos de or- 
ganización de masas [...] [por eso] me permitieron estar en algunas de las comisiones en las que desarrollaba ese trabajo, pertenecía a la comisión de organización del bloque donde militaba: Bloque Comandante Jorge Briceño, y hoy sigo perteneciendo a la comisión de organización del partido.

Ahora bien, Manuela cree en la educación con enfoque de género como una opción para construir la paz desde su transversalización en todos los asuntos educativos y los planes de estudio a partir de cambios en la cultura educativa y de la participación de las mujeres en la construcción de los proyectos educativos: "en el modelo educativo se abren esas posibilidades políticas académicas y culturales también para que las mujeres participemos no solamente de los ejercicios educativos, si no en el diseño de esos ejercicios educativos".

No obstante, Manuela reitera la importancia de enseñar en los colegios historia observando los fenómenos desde diferentes perspectivas con la posibilidad de asumir posiciones propias para evitar nuevos episodios de violencia.

Esta afirmación que hace Manuela se relaciona con una educación para la paz que tenga un carácter emancipador, y especialmente cuando los desafíos están orientados por los propósitos de superar los estragos de una guerra o de un conflicto armado.

Por ello, Galtung (2014) en su artículo titulado "La geopolítica de la educación para la paz: aprender a odiar la guerra, a amar la paz y a hacer algo al respecto", explica que

la educación para la paz tiene que preocuparse no solo por la proyección de imágenes de los horrores de la guerra, el sufrimiento y sus costes (lo cual se hace fácilmente), y las imágenes de los encantos de la paz, los disfrutes y sus beneficios (lo cual es más difícil; ya que la vida ordinaria, se refiere a lo que es la "paz", lo que significa 
que los verdaderos estudios para la paz tienen que tener un tinte utópico para ir más lejos de la no-guerra - que está más allá de los datos y dentro del reino de la imaginación-). La educación para la paz tiene que estar preocupada por lo que se debe hacer al respecto, lo que significa que no tiene que haber solo una teoría para evitar la guerra y construir la paz, pero sí una teoría realizable, vinculada a algún tipo de práctica para los que estudian esta materia, no solo para "otros". (p. 10).

Finalmente, desde la experiencia de La Habana con la conformación de la Subcomisión de Género en el proceso de concertación de los acuerdos de paz, Manuela encuentra en la igualdad de género una opción para construir la paz:

Pues creo que la igualdad de género es determinante no solamente en la construcción de la paz de Colombia sino en cualquier otro conflicto en el mundo que se pretende resolver. Lo que hicimos en La Habana con el enfoque de género fue inédito en la medida en que ningún otro conflicto en el mundo había tenido en cuenta las particularidades de las mujeres y si no se tienen en cuenta las particularidades de las mujeres en el marco del conflicto, en una sociedad en la que somos más del $50 \%$ y en el que vivimos de manera más profunda y específica todo tipo de violencia, pues definitivamente la paz no va a resolverse, es decir, la paz no va a llegar y no se va a construir. Al contrario, creo que vamos a entrar en un capítulo en el que si bien se zanjan algunas dificultades, esas profundidades van a quedar allí y luego van necesariamente a surgir nuevamente, y van hacer que la sociedad esté eternamente en los conflictos que no van a ser resueltos, entonces creo que es determinante tenerlo en cuenta porque esas problemáticas de las mujeres están allí hoy vivas y latentes, pues si logramos resolverlas definitivamente, el país va a entrar en una onda distinta y el momento distinto. 
Esta expresión de lo que significa para Manuela el camino para construir la paz — no siendo ajenos a la necesidad de resolver problemas relacionados con la violencia directa, cultural y estructural que viven las mujeres tanto en la sociedad en general como en el marco del conflicto armado, en donde la igualdad de género es planteada como una opción para construir la paz- nos conduce a los planteamientos de Galtung sobre su teoría de las tres R (1998) (sobre reconstruir, resolver y reconciliar); respecto a la reconstrucción se considera que pasar de los acuerdos de paz a la consolidación de la paz exige:

a) rehabilitación, que implica buscar la curación del daño y abolir la conducta violenta; b) reconstrucción física y económica de lo dañado, lo que pone en el centro el desarrollo humano sostenible, acordado en diálogo con la ciudadanía; c) reconfiguración de las estructuras, a partir de democracia y participación, y d) reculturización, o lo que es lo mismo, introducción de la educación para la paz y la resolución de conflictos en todos los niveles educativos. (Cámara de Comercio de Bogotá y Organización de Estados Iberoamericanos, 2019, p. 51).

\section{Conclusiones}

En relación con la pregunta inicialmente planteada en esta fase exploratoria de la investigación, sobre cuál es el rol de la mujer en la construcción de la paz y cuáles son las condiciones de formación más apropiadas para potenciar su liderazgo, en el camino hacia una paz perdurable y sostenible, se concluye inicialmente, en una aproximación al problema, que hay aspectos claves hacia donde orientar una educación para la paz con perspectiva de género en el contexto colombiano del potsconflicto, como los siguientes:

El papel de las mujeres en la construcción de paz está asociado a su participación en el camino hacia la consolidación de esta desde lo político, lo económico, lo ambiental, lo ecológico, así como desde la reconstrucción del tejido social, la obtención de justicia, y 
la recuperación de sus comunidades y entornos inmediatos afectados por el conflicto. Todo esto implica el reconocimiento, fortalecimiento y generación de oportunidades y condiciones para el pleno desarrollo de sus potencialidades.

Lo anterior indica que una propuesta de educación para la paz con enfoque de género implica comprender que la educación nunca podrá estar de espaldas a las realidades sociales, toda vez que de una u otra forma está permeada por e incide en ellas. En el caso colombiano las realidades sociales están vinculadas de distintas maneras con el conflicto armado, así como con los cambios estructurales que se esperan con la implementación de los acuerdos de paz, todo esto con la esperanza de lograr consolidar acciones que incidan en el cierre de las brechas de desigualdad que afectan la calidad de vida de las personas. En este contexto la educación para la paz con perspectiva de género juega un papel protagónico en la formación en todos los niveles educativos para lograr la eliminación de la violencia directa, cultural y estructural, teniendo en cuenta su impacto en el individuo, la familia, la comunidad y la sociedad.

De acuerdo con los resultados, es preciso destacar cómo los excombatientes dan un lugar prioritario a la necesidad de seguridad frente a su percepción de peligro por el riesgo de muerte a líderes sociales, lo que hoy es una triste realidad en el contexto colombiano, siendo vigente esa percepción desde el momento en que fueron encuestados, cuando era reciente la firma de los acuerdos de paz.

Frente a esta situación, una educación para la paz con perspectiva de género ha de formar en el respeto a la diversidad y a la diferencia; en el reconocimiento de las capacidades y potencialidades de las mujeres, el desarrollo de su autonomía, su empoderamiento y la generación de condiciones para su participación, y de su capacidad de independencia, su seguridad, su libertad y su ejercicio político, con una postura firme y declarada desde un enfoque de derechos, en donde el derecho a la vida se materialice en pensamientos, valores y acciones que se extrapolen de los ambientes de 
aprendizaje de las instituciones educativas a la sociedad y viceversa en esa conexión entre educación y sociedad.

Una propuesta de educación para la paz con perspectiva de género ha de incidir en la consolidación de proyectos de vida personales y colectivos de hombres y mujeres, puesto que de cara a lo que socialmente ha dejado el conflicto armado colombiano, muchas mujeres han expresado su capacidad de resiliencia y con ello sus deseos de superación no solo personal sino también familiar, comunitaria y social. En este sentido, la educación debe formar para la participación, la convivencia, la no violencia, la generación de nuevas masculinidades y contribuir al fortalecimiento de los movimientos sociales en favor de la igualdad de género.

\section{Referencias bibliográficas}

Ahmed Ali, A. F. (2015). Mujeres y guerra: deconstruyendo la noción de víctimas y reconstruyendo su papel de constructoras de paz. Castelló de la Plana: Universitat Jaume I.

Amorós, C. y Miguel, A. de. (eds.) (2010). Teoría feminista: de la ilustración a la globalización (vol. 3: de los debates sobre el género al multiculturalismo) (2. a ed.). Madrid: Minerva.

Calderón, P. (2009). Teoría de conflictos de Johan Galtung. Revista de Paz y Conflictos, 2, 60-81.

Cámara de Comercio de Bogotá y Organización de Estados Iberoamericanos. (2019). Construcción de paz y valor compatido. Bogotá: Cámara de Comercio de Bogotá y Organización de Estados Iberoamericanos.

Cepal. (2016). Autonomía de las mujeres e igualdad en la agenda de desarrollo sostenible. Santiago: Naciones Unidas.

Christiansen, M. (2013). Violencia y maltrato en las ecologías relacionales: hacia una epistemología de la corresponsabilidad. Interpersona: An 
International Journal on Personal Relationships, 7(1), 150-163. DOI: https://doi.org/10.5964/ijpr.v7i1.115

Fundación Paz y Reconciliación. (2017). Terminó la guerra, el postconflicto está en riesgo. Buenos Aires: Clacso.

Galtung, J. (2014). La geopolítica de la educación para la paz: aprender a odiar la guerra, a amar la paz y a hacer algo al respecto. Revista de Paz y Conflictos, 7, 9-18.

Magallón, C. (2006). Mujeres en pie de paz: pensamiento y prácticas. Madrid: Siglo XXI.

Miguel, A. de (2005). La violencia de género: la construcción de un marco feminista de interpretación. Recuperado de http://www.mujeresenred. net/spip.php?article440

Miguel, A. de (2017). Neoliberalismo sexual: el mito de la libre elección. Madrid: Cátedra.

ONU Mujeres y POTI (Peace Operations Training Institute). (2013). Implementación de las resoluciones del Consejo de Seguriridad de la ONU sobre la agenda de la mujer, la paz, y la seguriridad en Améririca Latina y el Caribe. Recuperado de https://cdn.peaceopstraining.org/ course_promos/wps_lac/wps_lac_spanish.pdf

Quesada, F. (2014). Mujeres y guerra: cuerpos, territorios y anexiones. Madrid: Biblioteca Nueva.

Unesco. (2017). La Unesco avanza: la Agenda 2030 para el Desarrollo Sostenible. Recuperado de http://www.unesco.org/new/fileadmin/ MULTIMEDIA/FIELD/Hanoi/2030_Brochure_SP.pdf 